addition to the quota available for ordinary use to the distributor. Only they forgot that an unscrupulous publican can inhibit all ordinary sales and provide distribution only by provision of a medical certificate for same, and as his supply of the latter is reimbursed for each medical certificate provided, the more medical certificates he receives the greater facility he is provided with to dispose of his weekly quota at gratifying prices to himself. That honest hostelers do exist, distributing their quota in fair portion to all their customers while still reserving a small percentage for immediate essential medical use, rather proves that the original reservation is not essential, nor in fact desirable.

This allegorical approach enables me to state with conviction that I have never seen half a valuable page of the Journal put to a greater degree of useless blether than is contained in the Supplement of March 15 (p. 33) describing what is apparently a face-saving measure for the original restrictions imposed on such an essential female garment as a corset, such measure in any case still stimulating the corsetière to obtain a quota-free corset for her client in preference to the private made-tomeasure article, as the former is still apparently available free of purchase tax.

I note these arrangements have not been drawn up in consultation with the manufacturers, and venture to suggest that their advice might have been taken as to how they have successfully surmounted the prolonged epidemic of "severe visceroptosis" despite their shortage of skilled labour. The matter undoubtedly may now be left to their initiative in the confidence that essential demands will be met and the initiation of visceroptotic anxiety left to the hands of the charlatan.I am, etc.,

Tipton, Staffs.

L. H. Eunson.

\section{Diet and Canine Hysteria}

SIR,- Sir Edward Mellanby's notion that canine hysteria was produced by feeding growing dogs on agenized flour (Dec. 14, 1946 , p. 885) cannot be reconciled with experience of the behaviour of healthy dogs or the pathology of those diseased dogs which exhibit canine hysteria. It is very difficult to assess Sir Edward's data, since he omitted to correlate his clinical observations with the ante- and post-mortem pathology of his laboratory dogs and rats. Moreover, his statement that fits were observed "in the animals receiving treated [agenized] flour and were never seen in those having untreated flour" was qualified by his earlier statement that fits "could often be produced" by feeding agenized flour. [my italics].

It would seem that some of the dogs which were fed on agenized flour did not show fits, but I cannot find any description of them: they are not illustrated in Sir Edward's three tables; they obtained even less notice than the rats, which were uniformly negative. This evidence should have been detailed since it is consistent with the anomalies of naturally occurring canine hysteria, of which I will cite two examples from my own records:

(1) No further fits have been observed in the dogs whose diet has been changed from biscuit to meat, whereas fits have persisted in some of the dogs whose diet (biscuit) has been maintained. Some observers have been misled by this phenomenon into attributing the cause of canine hysteria to certain dog biscuits. But I have studied canine hysteria in dogs which, since weaning, had been fed exclusively on meat. (2) No further fits have been observed in the dogs from which roundworms have been expelled, whereas fits have persisted in some of the untreated dogs, although no change has been made in the diet. Many have been influenced by this phenomenon into attributing canine hysteria solely to roundworms. For an understanding of the clinical phenomena the pathology must be fully studied.

My observations of naturally occurring canine hysteria have been incorporated in papers on the B.H.S. infection, which is a widely adopted abbreviation for the infection by various Lancefield groups of the $\beta$-haemolytic streptococcus (Hare and Fry, 1938 ; Hare, 1946). Canine hysteria is not a disease entity it is an event which may occur in the course of a particular infection; it is a type of spasmophilia which is expressed by a proportion of dogs infected by the B.H.S. and roundworms (Toxascaris sp. and/or Toxocara sp.). The essential pathology of dogs which have been destroyed within 24 hours of showing canine hysteria is that of the B.H.S. infection plus the presence of a variable number of roundworms in the duodenum -i.e., chronic tonsillitis, hyperplasia of the reticulo-endothelial system, catarrh of the pylorus of the stomach and duodenum, albuminous degeneration of the liver and kidneys, and, as first recorded by the late Prof. John Eyre (1928), toxic encephalopathy.

In my cases I have not observed "loss of consciousness" and "epileptiform convulsions," which Sir Edward reported in some of his dogs. The label "epileptiform convulsions" (without loss of consciousness) was applied by nineteenth-century French and British veterinary authors to what is now termed canine hysteria. More recent work on the pathology has clarified the differential diagnosis of at teast four distinct types of spasmophilia of dogs, one of these types being epileptiform convulsions, which are now recognized as due to the B.H.S. infection complicated by coccidiosis. Unfortunately some authors carelessly apply the words "epileptiform convulsions" (with loss of consciousness) to the behaviour of dogs which are in the condition of hepatic and renal failure. This is the pathology of the terminal stage of several diseases, one of which is the conjoint B.H.S. and roundworm infections.

From Sir Edward's statement that " a time may come, however, when a dog which soems to be acquiring immunity suddenly suffers the most severe epileptiform fits and dies "I infer that his dogs, to which he attributed "epileptiform convulsions" and "loss of consciousness," were in a condition of hepatic and renal failure. Sir Edward's description of his dogs' behaviour, apart from "epileptiform convulsions" and "loss of consciousness," seems to me to be consistent with the symptomatology of naturally occurring canine hysteria, which was described in French and British veterinary literature of over 60 years ago. Sir Edward has been gravely misled into attributing our knowledge of canine hysteria to American sources of the past 30 years.

I find further support for my inference that Sir Edward's dogs were suffering from the B.H.S. and roundworm infections from his description of "the actual observed state of the affected animals" in such phrases as: "the attacks seem to represent temporary exacerbations superimposed on a chronic abnormal condition"; "in young puppies the attacks came on insidiously and usually took some weeks to develop"; "lactating bitches appear to be particularly prone to hysterical fits." I accept Sir Edward's diagnosis of his dogs' behaviour as canine hysteria, not his startling notion of its aetiology. In my opinion he experimented on diseased dogs and mistook the expressions of their disease for the consequences of his dietary changes. - I am, etc.

TOM HARE. REFERENCES

Eyre, J. W. H. (1928). Vet. J., 84, 183. (1938).' Vet. Rec., 50, 213, and Proc. N.V.M.A. Congress, (1946). Ibid, 58, 177

\section{Arsenical Encephalopathy}

SIR,-The report of a case of arsenical encephalopathy and its treatment, by Drs. G. Hipps and R. Goldberg (March 8, p. 296), calls for some comment. Though a case of this nature may be rare in this country it can by no means be described as " a rare clinical condition." Such cases were commonly met with in India Command in the years 1942-5, and a large number of deaths occurred from post-arsenical encephalopathy during that period. The condition was almost exclusively confined to Indian O.R.s, the majority being natives of Southern India. Though the diet of Indian troops varied a good deal in its constituents from that of British O.R.s, the part played by subclinical vitamin deficiency or by deficient intake of aminoacids containing the essential - SH grouping could not be determined in these fatal cases.

Though symptomatic treatment of effects due to organoarsenical intoxication is an important feature in the later stages of the syndrome, it is now known that specific treatment of the underlying chemo-pathology at an early stage will produce positive results. Recent work on the toxicity of arsenical compounds when injected into the body confirms the work of Voegtlin and his colleagues (Voegtlin, Dyer, and Leonard, 1923, 1925), who showed that organic compounds of the type R.As: As.R were inactive in that form but were oxidized in the body to the form R.As: $O$, and that only when they had undergone this change did they exert their toxic action either on the parasites or the host. They showed further that the 